\title{
Mentha spicata L. ve Mentha villoso-nervata L. genotiplerinin bazı uçucu yağ bileșenleri üzerine farklı azot ve fosfor dozlarının etkisi
}

\author{
Meryem YEȘiL ${ }^{1}$, Kemalettin KARA ${ }^{2}$
}

10rdu Üniversitesi Teknik Bilimler Meslek Yüksekokulu Bitkisel ve Hayvansal Üretim Bölümü, ORDU

${ }^{2}$ Atatürk Üniversitesi Ziraat Fakültesi Tarla Bitkileri Bölümü, ERZURUM

Alınış tarihi: 13 Mayıs 2017, Kabul tarihi: 15 Ekim 2017

Sorumlu yazar: Meryem YEȘiL, e-posta:meryemyesil@hotmail.com

\section{Öz}

Mentha spicata L. ve Mentha villoso-nervata L. genotiplerinin bazı uçucu yağ bileşenleri üzerine azot ve fosfor dozlarının etkilerini belirlemek amacıyla yapılan bu çalışma 2010 ve 2011 yıllarında Erzurum'da yürütülmüştür. Mentha spicata'ya ait iki ( 2 ve 6 no'lu) ve Mentha villoso-nervata'ya ait bir genotip (4 no'lu) ile üç azot $(0,5 \mathrm{ve} 10 \mathrm{~kg} / \mathrm{da}$ ) ve üç fosfor $(0,5,10 \mathrm{~kg} / \mathrm{da})$ dozunun kullanıldığ deneme "Şansa Bağlı Tam Bloklar Deneme Planına" göre üç tekrarlamalı olarak yürütülmüştür. Denemenin birinci yılında dekara $5 \mathrm{~kg}$ azot dozunda en yüksek $\alpha$-pinene, $\beta$-phellandrene, $\beta$-pinene, 3 -octanol oranları elde edilirken, ikinci yılında en yüksek $\alpha$ pinene, $\beta$-phellandrene, $\beta$-pinene, 3 -octanol ve $p$ cymol oranları azot uygulanmamış parsellerden elde edilmiştir. En fazla ortalama değerlere göre 2010 deneme yılında $\alpha$-pinene, $\beta$-phellandrene, $\beta$-pinene ve 3 -octanol oranları $5 \mathrm{~kg} / \mathrm{da}$ fosfor uygulamasinda öne çlkarken, 2011 deneme yılında $\alpha$-pinene ve $\beta$ phellandrene oranları fosfor gübrelemesi yapılmamış parsellerde tespit edilmiştir. $10 \mathrm{~kg} / \mathrm{da}$ fosfor gübrelemesinde ise $\beta$-pinene ve 3-octanol ve p-cymol oranları fazla olmuştur. Kullanılan azot ve fosfor dozu ortalamalarına göre; Mentha spicata'ya ait 6 no'lu genotip, her iki deneme yılında da $\beta$ phellandrene, p-cymol, ikinci deneme yılında $\alpha$ pinene ve 3-octanol oranları bakımından ön plana çıkmıştır. Mentha villoso-nervata'nın 4 no'lu genotipi ise 2010 deneme yılında diğer genotiplerden daha fazla $\alpha$-pinene, $\beta$-pinene ve 3 -octanol oranlarına sahip olmuștur. Mentha spicata'nın 2 no'lu genotipinde ise ikinci deneme yllında $\beta$-pinene ve 6 no'lu genotip ile birlikte en yüksek p-cymol oranı tespit edilmiştir.

Anahtar kelimeler: Tıbbi bitkiler, uçucu yağ, gübreleme

Effect of different nitrogen and phosphorus doses on some essential oil components of Mentha spicata L. and Mentha villoso-nervata L. genotypes

\section{Abstract}

This study was carried out in Erzurum in 2010 and 2011, in order to determine the effects of nitrogen and phosphorus doses on some essential oil components of Mentha spicata L. and Mentha villosonervata L. genotypes. An experiment using three nitrogen $(0,5$ and $10 \mathrm{~kg} / \mathrm{da})$ and three phosphorous $(0,5,10 \mathrm{~kg} / \mathrm{da})$ genotypes of two Mentha spicata (number 2 and 4) and one Mentha villoso-nervata (number 4) was carried out with three replications according to the "Randomized Full Blocks Experiment Plan". Whereas the highest ratios of $\alpha$ pinene, $\beta$-phellandrene, $\beta$-pinene, and 3-octanol at the dose of $5 \mathrm{~kg}$ of nitrogen per decare were obtained in the first year of the test, the highest ratios from parcels without nitrogen exposure were $\alpha$-pinene, $\beta$-phellandrene, $\beta$-pinene, and $p$-cymol per decare. According to the highest mean values; $\alpha$ pinene, $\beta$-phellandrene, $\beta$-pinene, and 3-octanol ratios in 2010 test year were obtained from parcels fertilised with phosphor at $5 \mathrm{~kg} / \mathrm{da}$, while the ratios from parcels without phosphor fertilisation in 2011 test year were identified as $\alpha$-pinene and $\beta$ phellandrene. $\beta$-pinene and 3-octanol and p-cymol 
ratios were in excess at $10 \mathrm{~kg} / \mathrm{da}$ phosphor fertilisation. According to mean values of nitrogen and phosphor doses used; the genotype number 6 of mentha spicata distinguishes itself in terms of $\beta$ phellandrene and p-cymol ratios in both test years, and for $\alpha$-pinene and 3-octanol ratios in the second test year. Compared to other genotypes, the genotype number 4 of Mentha villoso-nervata had more $\alpha$-pinene, $\beta$-pinene and 3 -octanol ratios in 2010 test year. The ratios of $\beta$-pinene in genotype number 2 of Mentha spicata as well as the highest pcymol in genotype number 6 were discovered in the second test year.

Key words: Medical plants, essential oil, fertilization

\section{Giriş}

Gübre üretimi ve tüketimi bir ülkenin tarımsal gelişmesinin olduğu kadar, birim alandan alınan ürün miktarının da en iyi göstergelerinden biridir. Gübreleme, sulama ile birlikte tarımsal üretimin tabii koşullara bağımlılığını azaltan en önemli etkendir. Dengeli ve ekonomik olmak koşulu ile gübrelemenin diğer tüm tarımsal girdilere göre bitkisel üretimdeki payının daha yüksek olduğu çeşitli ülkelerde yapılmış araştırmalarla kanıtlanmış durumdadır (Eyüpoğlu, 2002). Bütün zirai ürünlerde yüksek verimin önemli bir kriteri olan gübreleme işlemi tıbbi ve aromatik bitkilerde de gerek tarımsal gerekse kalite özellikleri üzerine önemli bir etki yapan girdi olarak kabul edilmektedir.

Tıbbi ve aromatik bir bitki olan nane uçucu yağının değerli olması nedeniyle birçok ülkede ticari olarak tarımı yapılmaktadır. Ülkemizde ise bahçelerde, evlerin önünde ve tarlalarda yetiștirilen nane bitkisi tıbbi açıdan spazm ve gaz giderici, midevi, serinletici, uyarıcı ve diüretik etkilere sahip olup, nane yaprakları baharat ve bitki çayları şeklinde de çok yaygın bir sekilde kullanılmaktadır. Nane yağı ilaç, gıda, içki ve kozmetik sanayiinde geniş bir uygulama alanı olan mentolun en zengin doğal kaynağıdır (Baytop, 1999).

Mentha spicata (M.viridis), spearmint esansı adı verilen uçucu yağı nedeniyle önemli bir türdür. Özel kokulu bu esans mentol taşımamaktadır. Bitkinin çok iyi bir rozmarinik asit kaynağı olduğu tespit edilmiştir. Diş macunlarına, ağız sularına ve çikletlere koku vermek için kullanılmaktadır (Tanker ve ark., 1998). Uçucu yağ oranları \%0.12-2.1, karvon oranları \%49-74 arasında değişmektedir (Telci, 2001).
Mentha longifolia L. Hudson ile Mentha spicata L. bitkilerinin melezlenmesi sonucu oluşmaktadır. Bitki çok yıllık, 20-70 cm boyunda, gövde küf veya keskin kokulu bir bitkidir. Rizomlar toprağın derinliklerinde yer almakta, uçucu yağ oranları \%0.4- 0.6 arasında değişmektedir. Karvonca zengin türleri baharat olarak kullanılır (Davis, 1982; Başer ve ark., 1999; Telci, 2001). Bitkiler steril olup, dere ve yol kenarlarında yayılış gösterirler. (Telci, 2001).

Bu çalışma; Erzurum şartlarında Mentha spicata (2 ve 6 no'lu genotip) ve Mentha villoso-nervata (4 no'lu genotip)'ya ait üç nane genotipinin bazı uçucu yağ bileșenleri üzerine farklı azot ve fosfor dozlarının etkilerini incelemek amacıyla yapılmıştır.

\section{Materyal}

\section{Denemede Kullanılan Materyal}

Denemede Tokat Gaziosmanpaşa Üniversitesi Ziraat Fakültesi Tarla Bitkileri Bölümünden temin edilen Labiatae familyasına ait Mentha türlerinden Mentha spicata'ya ait iki genotip (2 ve 6 no'lu genotipler) ve Mentha villoso-nervata Opiz'e ait bir genotip (4 no'lu genotip) kullanılmıştır. Bu genotipler Erzurum ili vejetasyonuna ve iklimine daha kolay adaptasyon sağlayacağı düşünüldüğü için tercih edilmiştir.

\section{Deneme Yeri}

Araștırma, Atatürk Üniversitesi Ziraat Fakültesi'ne ait 4 no'lu deneme alanında 2010 ve 2011 yıllarında yürütülmüştür.

\section{Araştırma Sahasının Toprak Özellikleri}

Deneme alanının 0-20 cm derinlikten alınan örneklerin analizi sonucunda toprak bünyesinin killitınlı, p pH'sının ise 7.27 olduğu belirlenmiştir. Organik madde miktarı \%0.11, bitkilere yarayışlı $\mathrm{P}_{2} \mathrm{O}_{5} 14.2 \mathrm{~kg} / \mathrm{da}, \mathrm{K}_{2} \mathrm{O}$ ise $163.6 \mathrm{~kg} /$ da dir. Bu verilere göre, deneme alanı toprakları hafif alkali karakterde, bitkilere yarayışlı fosfor orta, potasyumca zengin ve organik maddece fakir durumdadır (Sezen 1991).

\section{Denemede Kullanılan Gübreler}

Fosforlu gübre olarak triple süperfosfat (\%45) ve azotlu gübre olarak da amonyum sülfat (\%21) gübreleri kullanılmıştır. Azotlu ve fosforlu gübreler tek parça halinde denemenin birinci yılında dikim ile birlikte, ikinci yılında ise ilkbaharda verilmiştir.

\section{Hasat}

Nane genotiplerinin çiçeklenme başlangıçları dikkate alınarak; 2010 yılında 6 no'lu genotip 10 Ağustos'ta, 2 ve 4 no'lu genotipler 16 Ağustos'ta hasat edilmiştir. 2011 yllında ise hasat, 6 no'lu genotip için 11 
Ağustos, 2 ve 4 no'lu genotipler 23 Ağustos tarihlerinde olmak üzere yılda bir kez gerçekleştirilmişir.

\section{Kurutma}

Uçucu yağı elde edilen bitki yaprakları $35^{\circ} \mathrm{C}$ sıcaklıktaki kurutma firınında kurutulmuştur.

\section{Araştırma Sahasının İklim Özellikleri}

Erzurum ili, Türkiye'nin kuzey doğusunda 39055' kuzey enlemi ve 41061' doğu boylamında yer alan ve 1853 m'lik rakıma sahip, karasal iklimin hüküm sürdüğü bir ilimizdir. Karasal iklim ve yüksek rakım nedeniyle gerek mevsimler gerekse gece ve gündüz arasındaki sıcaklık farkları çok fazladır.

Çizelge 1. Denemede kullanılan nane genotiplerin orjinleri

\begin{tabular}{cc}
\hline Genotipler & Orjin \\
\hline M.spicata 2 no'lu genotip & Çorum \\
M.villoso nervata 4 no'lu genotip & Amasya \\
M.spicata 6 no'lu genotip & Tokat \\
\hline
\end{tabular}

Çizelge 2. Erzurum İlinin uzun yıllar ile 2009, 2010 ve 2011 yıllarına ait bazı önemli iklim verileri

\begin{tabular}{|c|c|c|c|c|c|c|c|c|c|c|c|c|c|}
\hline \multirow[t]{2}{*}{ Yıllar } & \multicolumn{13}{|c|}{ Aylar } \\
\hline & 0 & Ş & $M$ & $\mathrm{~N}$ & $M$ & $\mathrm{H}$ & $\mathrm{T}$ & $\mathrm{A}$ & $E$ & $\mathrm{E}$ & $\mathrm{K}$ & A & Top/Or \\
\hline \multicolumn{14}{|c|}{ Aylık Toplam Yağıș (mm) } \\
\hline $\begin{array}{l}1990 \\
2009\end{array}$ & 14.5 & 20.6 & 35.1 & 57.1 & 64.6 & 42.6 & 23.1 & 14.3 & 21.8 & 43.8 & 29.9 & 21.8 & $383.2 / 32.4$ \\
\hline 2009 & 2.3 & 18.8 & 51.1 & 42.3 & 43.2 & 76.2 & 29.2 & 22.8 & 43.7 & 51.0 & 41.4 & 15.1 & $437.1 / 36.4$ \\
\hline 2010 & 52.2 & 14.8 & 82.2 & 54.2 & 63.6 & 50.5 & 55.5 & 9.0 & 8.8 & 72.2 & 0.0 & 12.9 & $475.9 / 39.7$ \\
\hline 2011 & 23.4 & 22.3 & 17.1 & 147.7 & 105.2 & 55.3 & 26.6 & 21.8 & 7.5 & 23.1 & 13.6 & 9.2 & $472.8 / 39.4$ \\
\hline \multicolumn{14}{|c|}{ Aylık Ortalama Sıcaklık ( $\left.{ }^{\circ} \mathrm{C}\right)$} \\
\hline $\begin{array}{l}1990 \\
2009\end{array}$ & -11.2 & -9.6 & -2.9 & 5.1 & 10.4 & 14.7 & 19.0 & 19.2 & 13.7 & 7.6 & 0.4 & -7.3 & $58.3 / 4.8$ \\
\hline 2009 & -12.1 & -3.1 & 0.7 & 4.3 & 10.0 & 14.7 & 17.2 & 17.1 & 12.4 & 8.7 & 1.8 & -1.1 & $69.2 / 5.7$ \\
\hline 2010 & -4.3 & -1.8 & 3.1 & 5.6 & 10.4 & 15.9 & 19.5 & 20.3 & 17.0 & 9.2 & 1.8 & -1.9 & $94.8 / 7.9$ \\
\hline 2011 & -8.4 & -7.7 & -1.5 & 5.6 & 9.6 & 14.6 & 19.6 & 19.4 & 13.9 & 6.7 & -5.5 & -11.4 & $54.9 / 4.6$ \\
\hline \multicolumn{14}{|c|}{ Aylık Ortalama Nispi Nem (\%) } \\
\hline $\begin{array}{l}1990 \\
2009\end{array}$ & 77.7 & 77.1 & 75.4 & 67.7 & 63.1 & 58.9 & 53.7 & 50.8 & 53.0 & 65.3 & 73.6 & 79.0 & $795.3 / 66.3$ \\
\hline 2009 & 82.4 & 84.7 & 73.8 & 64.6 & 61.0 & 65.0 & 60.7 & 50.6 & 53.1 & 62.4 & 75.7 & 84.7 & $818.7 / 68.2$ \\
\hline 2010 & 84.0 & 82.3 & 69.1 & 71.3 & 69.6 & 60.1 & 56.0 & 44.8 & 48.1 & 70.2 & 66.1 & 76.6 & $798.2 / 66.5$ \\
\hline 2011 & 81.2 & 79.8 & 75.0 & 72.1 & 69.5 & 63.4 & 53.3 & 48.2 & 53.8 & 62.0 & 79.7 & 82.5 & $820.5 / 68.4$ \\
\hline
\end{tabular}

*Erzurum Meteoroloji Bölge Müdürlüğ̈ yıllık rasatlarından alınmıştır.

\section{Yöntem}

\section{Deneme Deseni}

Atatürk Üniversitesi Ziraat Fakültesine ait araştırma sahasında yürütülen bu denemede iki türe ( $M$. spicata ve $M$. villoso-nervata) ait 3 genotip, üç azot ve üç fosfor dozu (0 kg/da, $5 \mathrm{~kg} / \mathrm{da}, 10 \mathrm{~kg} / \mathrm{da})$ yer almıştır. Araştırma, Şansa Bağlı Tam Bloklar Deneme Planına göre 3 tekrarlamalı olarak düzenlenmiştir (Ylldı, 1994). Parsel boyu 3.6 m, eni 1.6 m olurken, parsel alanı $5.76 \mathrm{~m}^{2}$ olmuştur. Genotiplerin dikimi $40 \mathrm{~cm}$ sıra arası, $30 \mathrm{~cm}$ sıra üzeri mesafelerine göre düzenlenmiş, her parsel 4 sıradan oluşmuştur. Denemede parsel sayısı 81 adet olurken toplam

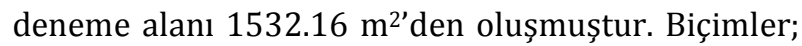
birinci deneme yılında parsel kenarlarından birer sıra ve baş kısımlardan $30 \mathrm{~cm}$ kenar tesiri bırakılarak geri kalan alan hasat edilerek yapılmıştır. İkinci deneme yılında ise nane bitkilerinin toprağa yayılarak sıra arası ve sıra üzeri mesafeleri kapatması sebebi ile 200 x $80 \mathrm{~cm}$ ebadında çerçeve kullanılarak bu alana düşen bitkiler hasat edilmiștir.

\section{Uçucu yağın elde edilmesi ve bileşenlerinin belirlenmesi}

Distilasyon yöntemi (su buharı ile sürükleme), uçucu yağ elde etmede en çok kullanılan yöntem olduğu için tercih edilmiştir. Yaprak numuneleri 350C'de kurutma firınında kurutulup öğütülmüştür. Distilasyon balonuna 40 gr öğütülmüş yaprak numunesi konularak üstüne $1000 \mathrm{ml}$ su ilave edilmiş, balon mantolu isıtıcı ile $1200^{\circ} \mathrm{C}$ yi aşmayacak bir sıcaklıkta ısıtılmıştır. Üç saat süren ısıtma işleminin ardından düzeneğin 5-10 dakika kadar soğuması beklenmiş ve su yüzeyinde toplanmış olan uçucu yağ cam viallere aktarılıp etiketlenerek analizler yapılıncaya kadar $40^{\circ} \mathrm{C}$ 'de muhafaza edilmiştir (Kireçci 2006). 
Uçucu yağların bileşenleri Atatürk Üniversitesi Ziraat Fakültesi Gıda Bölümü Laboratuvarında GCMS (gaz kromatografisi/kütle spektrometrisi) ile belirlenmiştir. Sistemde kolon olarak HP1 (30 m x $0.25 \mathrm{~mm}$, film inceliği $0.25 \mu \mathrm{m}$ ) kullanılmış, taşıyıcı gaz olarak helyumdan yararlanılmıştır. GC-MS parametreleri şöyledir; MS kaynak sıcaklığı: $2300^{\circ} \mathrm{C}$; MS kuadrupol sıcaklığı: 1500C; iyonizasyon enerjisi: $70 \mathrm{eV}$; iyonizasyon akımı: $60 \mu \mathrm{A}$; tarama alanı: 35350 u; tarama/sec:4.51'dir (Martins Maldao ve ark., 2004). Uçucu yağlardaki bileşenlerin karakterizasyonu elektronik kütüphaneler Flavor2.L, Wiley7n.1, NIST98.L (Martins Maldao ve ark., 2004; Arslan ve ark., 2010) ve standart maddeler (karbon standartları, $\alpha$-pinene, $\beta$-pinene, terpinene, carveol, menthone, limonene, terpinen-4-ol, pulegone, piperitone, 1.8-cineole, linalool, carvone, menthol) kullanılarak yapılmıştır.

\section{Bulgular ve Tartışma}

İncelenen bütün uçucu yağ bileşenlerinin ( $\alpha$-pinene pranı, $\beta$-phellandrene oranı, $\beta$-pinene oranı, 3octanol oranı ve p-cymol oranı) oranı üzerinde azot dozlarının, fosfor dozlarının ve kullanılan genotiplerin 2010-2011 deneme yıllarında önemli fark $(\mathrm{p}<0.01)$ oluşturduğu tespit edilmiştir (Çizelge 4, Çizelge 6, Çizelge 8, Çizelge 10, Çizelge 12).

\section{$\alpha$-pinene Oranı}

Deneme yıllarında $\alpha$-pinene oranında, artan azot dozlarına paralel olarak artış meydana gelmemiș, en fazla $\alpha$-pinene oranı birinci deneme yılında $5 \mathrm{~kg}$ 'lık azot dozunda (\%0.13), ikinci deneme yllında ise 0 kg'lık dozda (\%0.23) belirlenmiştir. En düşük $\alpha$ pinene oranı ise birinci deneme yılında $0 \mathrm{~kg}$ 'lık dozda (\%0.05), ikinci deneme yllında ise $10 \mathrm{~kg}$ 'lı azot dozunda (\%0.19) tespit edilmiștir (Çizelge 3).

Fosfor uygulamalarına göre; en fazla $\alpha$-pinene oranı birinci deneme yılında $5 \mathrm{~kg}$ fosfor dozunda (\%0.11), denemenin ikinci yılında ise 0 kg'lık dozda (\%0.24) tespit edilmiştir. En az $\alpha$-pinene oranı ise birinci deneme yllında fosfor uygulanmayan genotiplerden (\%0.08), ikinci deneme yılında ise dekara $5 \mathrm{~kg}$ fosfor dozunda (\%0.16) belirlenmiştir (Çizelge 3).

Çalışmada gübre dozlarına göre tespit edilmiş olan $\alpha$-pinene oranı literatürde yer alan değerlerden yüksek (\%0.09) veya aynı aralıkta (\%0.1-0.2) olmuştur (Kokkini et. al., 1995; Chauhan et. al., 2009; Kofidis ve ark., 2004; Telci, et. al., 2010). Bu durumun uygulanan farklı gübre dozlarından kaynaklandığı düşünülmektedir.

Birinci deneme yılında en yüksek $\alpha$-pinene oranı 4 no'lu genotipte $(\% 0.11)$ tespit edilmiş, bunu 6 no'lu $(\% 0.08)$ ve 2 no'lu genotip (\%0.07) izlemiştir. İkinci deneme yılında en fazla $\alpha$-pinene oranı 6 no'lu genotipte (\%0.24) belirlenmiş, bunu 2 no'lu (\%0.21) ve 4 no'lu genotip (\%0.17) takip etmiştir (Çizelge 3). Çalışmadan elde edilen bulgular, Clark and Menary (1982)'nin bildirdiği gibi uçucu yağ bileşenlerinin bitkinin genetik yapısı ile iklim koşullarına bağlı olarak değişebildiğini ortaya koymaktadır.

Çizelge 3. Azot ve fosfor dozlarına göre nane genotiplerinin $\alpha$-pinene oranı (\%)

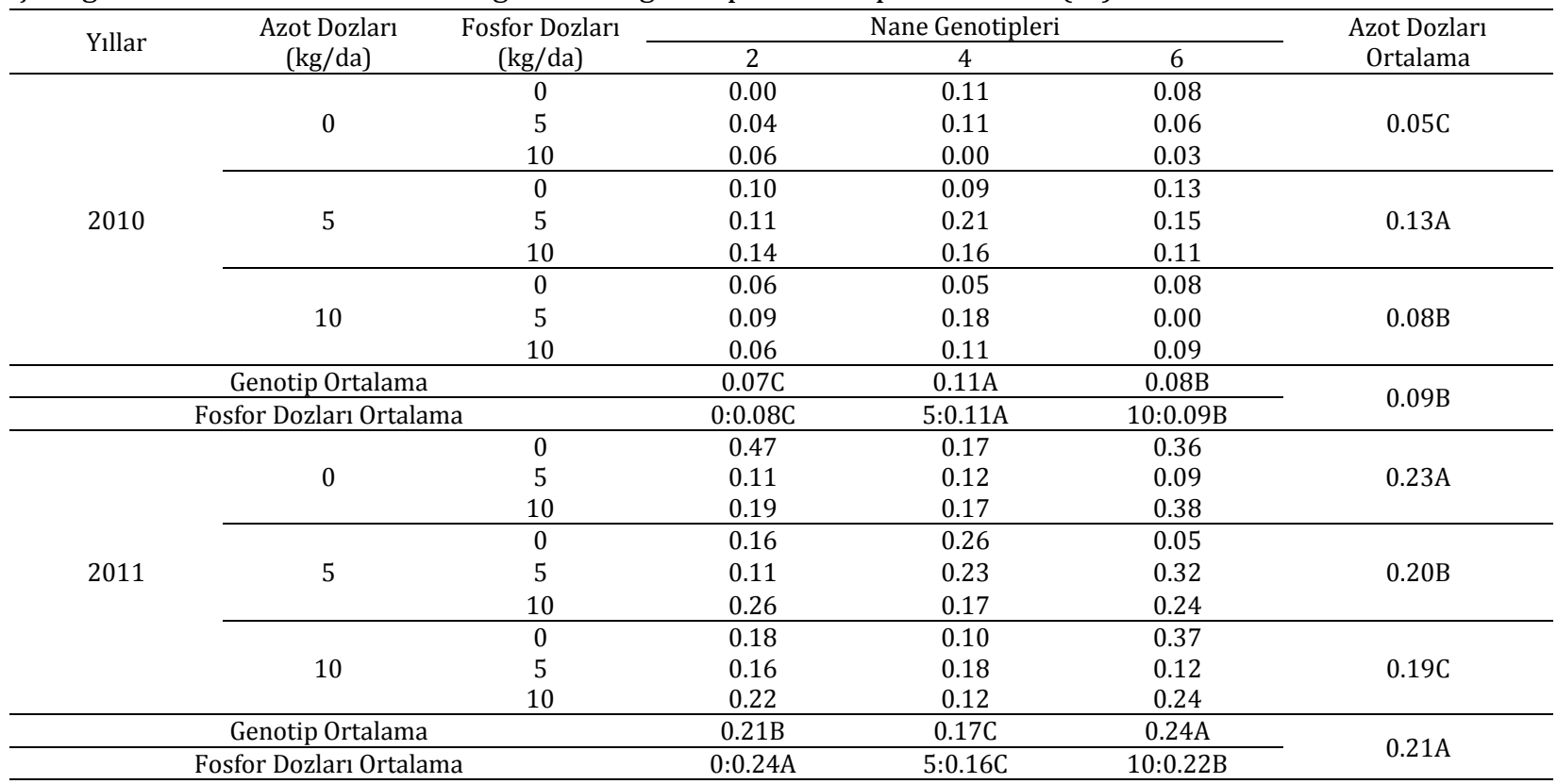


Çizelge 4. Azot ve fosfor dozlarına göre nane genotiplerinin $\alpha$-pinene oranına ait varyans analiz sonuçları

\begin{tabular}{cccc}
\hline Varyasyon Kaynakları & SD & 2010 & F değerleri \\
\cline { 2 - 4 } & & $470.934^{* *}$ & 2011 \\
Azot (A) & 2 & $60.013^{* *}$ & $93.076^{* *}$ \\
Fosfor (F) & 2 & $27.750^{* *}$ & $75.500^{* *}$ \\
Genotipler (G) & 2 & $32.717^{* *}$ & $103.107^{* *}$ \\
AxF & 4 & $13.237^{* *}$ & $38.286^{* *}$ \\
AxG & 4 & $97.730^{* *}$ & $38.500^{* *}$ \\
FxG & 4 & $56.579^{* *}$ & $79.929^{* *}$ \\
AxFxG & 8 & & \\
Hata & 54 & & \\
\hline
\end{tabular}

*İşaretli F değerleri $(\mathrm{p}<0.05),{ }^{* *}$ işaretli F değerleri ise $(\mathrm{p}<0,01)$ ihtimal sınırında önemlidir.

\section{$\beta$-phellandrene oranı}

Birinci deneme yllinda $\beta$-phellandrene oranı $5 \mathrm{~kg}$ azot dozunda en yüksek olmuş $(\% 0.23)$ bu dozdan sonra $10 \mathrm{~kg} \mathrm{l}^{\prime} \mathrm{lk}$ azot dozunda $(\% 0.15)$ azalmıştır.
İkinci deneme yılında ise dekara uygulanan azot dozu arttıkça $(0,5,10 \mathrm{~kg}) \beta$-phellandrene oranında düşüş meydana gelmiştir $(\% 0.23, \% 0.20, \% 0.19)$ (Çizelge 5).

Çizelge 5. Azot ve fosfor dozlarına göre nane genotiplerinin $\beta$-phellandrene oranı (\%)

\begin{tabular}{|c|c|c|c|c|c|c|}
\hline \multirow{2}{*}{ Yıllar } & \multirow{2}{*}{$\begin{array}{l}\text { Azot Dozları } \\
(\mathrm{kg} / \mathrm{da})\end{array}$} & \multirow{2}{*}{$\begin{array}{c}\text { Fosfor Dozları } \\
(\mathrm{kg} / \mathrm{da})\end{array}$} & \multicolumn{3}{|c|}{ Nane Genotipleri } & \multirow{2}{*}{$\begin{array}{c}\text { Azot Dozlar } \\
\text { Ortalama }\end{array}$} \\
\hline & & & 2 & 4 & 6 & \\
\hline \multirow{9}{*}{2010} & \multirow{3}{*}{0} & 0 & 0.00 & 0.00 & 0.33 & \multirow{3}{*}{$0.10 \mathrm{C}$} \\
\hline & & 5 & 0.00 & 0.00 & 0.37 & \\
\hline & & 10 & 0.00 & 0.00 & 0.20 & \\
\hline & \multirow{3}{*}{5} & 0 & 0.16 & 0.00 & 0.62 & \multirow{3}{*}{$0.23 \mathrm{~A}$} \\
\hline & & 5 & 0.00 & 0.00 & 0.79 & \\
\hline & & 10 & 0.00 & 0.00 & 0.52 & \\
\hline & \multirow{3}{*}{10} & 0 & 0.00 & 0.00 & 0.38 & \multirow{3}{*}{$0.15 \mathrm{~B}$} \\
\hline & & 5 & 0.36 & 0.00 & 0.07 & \\
\hline & & 10 & 0.00 & 0.13 & 0.43 & \\
\hline \multicolumn{3}{|c|}{ Genotip Ortalama } & $0.06 \mathrm{~B}$ & $0.01 \mathrm{C}$ & $0.41 \mathrm{~A}$ & \multirow{2}{*}{$0.16 \mathrm{~B}$} \\
\hline \multicolumn{3}{|c|}{ Fosfor Dozları Ortalama } & $0: 0.16 \mathrm{~B}$ & $5: 0.18 \mathrm{~A}$ & $10: 0.14 \mathrm{C}$ & \\
\hline \multirow{9}{*}{2011} & & 0 & 0.47 & 0.17 & 0.36 & \multirow{3}{*}{$0.23 \mathrm{~A}$} \\
\hline & 0 & 5 & 0.11 & 0.12 & 0.09 & \\
\hline & & 10 & 0.19 & 0.17 & 0.38 & \\
\hline & & 0 & 0.16 & 0.26 & 0.05 & \multirow{3}{*}{$0.20 \mathrm{~B}$} \\
\hline & 5 & 5 & 0.11 & 0.22 & 0.32 & \\
\hline & & 10 & 0.26 & 0.17 & 0.24 & \\
\hline & \multirow{3}{*}{10} & 0 & 0.18 & 0.10 & 0.37 & \multirow{3}{*}{$0.19 \mathrm{C}$} \\
\hline & & 5 & 0.16 & 0.18 & 0.12 & \\
\hline & & 10 & 0.22 & 0.12 & 0.24 & \\
\hline \multicolumn{3}{|c|}{ Genotip Ortalama } & $0.21 \mathrm{~B}$ & $0.17 \mathrm{C}$ & $0.24 \mathrm{~A}$ & \multirow{2}{*}{$0.21 \mathrm{~A}$} \\
\hline \multicolumn{3}{|c|}{ Fosfor Dozları Ortalama } & $0: 0.24 \mathrm{~A}$ & $5: 0.16 \mathrm{C}$ & $10: 0.22 \mathrm{~B}$ & \\
\hline
\end{tabular}

*Büyük harfle işaretlenen ortalamalar arasındaki farklar ( $p<0.01)$, küçük harfle işaretlenenler ( $p<0,05)$ ihtimal sınırlarına göre önemlidir.

Denemenin birinci yllında dekara $5 \mathrm{~kg}$ uygulanan fosfor dozunda ise $\beta$-phellandrene oranı en fazla (\%0.18) olmuş bu dozdan sonra azalmıştır $(\% 0,14)$. Denemenin ikinci yllında en az $\beta$-phellandrene oranı $5 \mathrm{~kg}$ fosfor uygulamasindan (\%0.16), en fazla ise fosfor uygulaması yapılmamış genotiplerden $(\% 0.24)$ elde edilmiş, bunu $10 \mathrm{~kg}$ 'lk fosfor dozu $(\% 0.22)$ takip etmiştir (Çizelge 5). Bütün gübre dozlarında elde edilen $\beta$-phellandrene oranları Telci et. al., 2010'un M. spicata bitkisinde farklı ekolojik ortamların uçucu yağ bileșenlerine etkisini inceledikleri araștırmalarında elde edilen oranlardan düşük (\%0.25-2.95) olmuștur. Bunun sebebi olarak Marotti ve ark. (1993)'un belirttiği gibi uzun gün bitkisi olan nanenin verim ve yağ kompozisyonunun; gün uzunluğuna, iklim faktörlerine, bitkinin gelişme dönemine, fotoperiyoda ve vejetasyon süresine bağlı olduğu düşünülmektedir.

Her iki deneme yılında $\beta$-phellandrene oranı en fazla 6 no'lu genotipte $(\% 0.41, \% 0.24)$, en az ise 4 no'lu genotipte $(\% 0.01, \% 0.17)$ belirlenmiştir. 2 no'lu genotipte ise tespit edilen oranlar sırası ile $\% 0.06$ ve $\% 0.21$ olmuştur (Çizelge 5). 
Çizelge 6. Azot ve fosfor dozlarına göre nane genotiplerinin $\beta$-phellandrene oranına ait varyans analiz sonuçları

\begin{tabular}{cccc}
\hline Varyasyon Kaynakları & \multirow{2}{*}{ SD } & 2010 & F değerleri \\
\cline { 2 - 4 } & & 2011 & $126.808^{* *}$ \\
Azot (A) & 2 & $187.250^{* *}$ & $465.346^{* *}$ \\
Fosfor (F) & 2 & $2893.750^{* *}$ & $377.423^{* *}$ \\
Genotipler (G) & 2 & $355.750^{* *}$ & $489.577^{* *}$ \\
AxF & 4 & $3139.375^{* *}$ & $176.827^{* *}$ \\
AxG & 4 & $427.000^{* *}$ & $178.385^{* *}$ \\
FxG & 4 & $1619.313^{* *}$ & $392.394^{* *}$ \\
AxFxG & 8 & & \\
Hata & 54 & & \\
\hline
\end{tabular}

*Işaretli F değerleri ( $\mathrm{p}<0.05),{ }^{* *}$ işaretli $\mathrm{F}$ değerleri ise $(\mathrm{p}<0.01)$ ihtimal sınırında önemlidir.

\section{$\boldsymbol{\beta}$-pinene oranı}

Denemenin ilk yılında, $\beta$-pinene bileşeni dekara $5 \mathrm{~kg}$ azot uygulamalarında en fazla $(\% 0.24)$ olmuş, ikinci deneme yllında ise en fazla $\beta$-pinene oranı azot uygulanmayan muamelelerden $(\% 0.9)$ elde edilmiştir. Denemenin ikinci yılında dekara 5 ve 10 $\mathrm{kg}$ azot uygulamalarında eşit oranda $\beta$-pinene oranı (\%0.30) belirlenmiştir. En az $\beta$-pinene bileşeni birinci deneme yılında azot uygulanmayan muamelelerden (\%0.13) elde edilmiștir (Çizelge 7).

Fosfor dozu bakımından 2010 deneme yılında en yüksek $\beta$-pinene oranı dekara $5 \mathrm{~kg}$ 'lı fosfor dozunda $(\% 0.20)$, denemenin ikinci yılında ise dekara $10 \mathrm{~kg}$ fosfor dozunda (\%0.37) elde edilmiștir. En düșük $\beta$ pinene oranı ise birinci deneme yılında fosfor uygulanmayan muamelelerden (\%0.15). ikinci deneme yılında ise dekara $5 \mathrm{~kg}$ fosfor uygulamalarında $(\% 0.26)$ tespit edilmiştir (Çizelge 7). Hem azot hem de fosfor uygulamaları sonucu elde edilen $\beta$-pinene oranları Hadjiakhoondi ve ark., 2000'nin İran'da M. spicata bitkisinin kimyasal kompozisyonunu belirlemek için yaptıkları çalışmada elde ettikleri değerden düşük $(\% 0,88)$, Chowdhury ve ark., 2007'nin Bangledesh'te $M$. spicata bitkisinde yürüttükleri çalışma sonucu elde ettikleri bulgudan (\%0.00) yüksek olmuştur. Bulgular arasındaki farkın sebebi olarak Ceylan (1989)'ın belirtmiş olduğu gibi nane türlerinin iklim ve toprak istekleri bakımından geniş bir tolerans göstermesine rağmen verim ve kalite özelliklerinin ekoloji ve kültürel işlemlerden önemli șekilde etkilenmiş olduğu düşünülmektedir.

$\beta$-pinene oranı ilk deneme yılında en fazla 4 no'lu genotipte $(\% 0.24)$, ikinci deneme yılında 2 no'lu genotipte (\%0.43) saptanmıştır. En az $\beta$-pinene oranı ilk deneme yılında 2 no'lu genotipte (\%0.13), ikinci deneme yılında ise 4 no'lu genotipte $(\% 0.15)$ belirlenmiştir (Çizelge 7). Bu bulgu, nanenin uçucu yağ oranının ve kompozisyonunun genetik faktörlere bağlı olduğunu belirten araştırıcılar tarafindan da desteklenmektedir (Misra ve ark. 1989; Kokkini 1991; Özgüven ve Kırıcı 1999).

\section{3-octanol oranı}

Uygulamaların ortalamalarına göre genotiplerden elde edilen 3-octanol oranı birinci deneme yllında (\%0.52), ikinci deneme yllına göre (\%0.47) fazla olmuştur (Çizelge 9). Birinci deneme yılında 3octanol oranının ikinci yıla göre fazla olması, bu yıldaki toplam yağışın (178.6 mm/208.9 mm) ve nispi nemin (\%57.6/\%58.6) ikinci yıla göre düşük, sıcaklığın (66.10C/63.30C) yüksek olmasından kaynaklanabilir (Çizelge 2).

Denemenin birinci yılında en yüksek 3-octanol oranı (\%0.62) dekara $5 \mathrm{~kg}$ azot uygulamasinda tespit edilmiştir. Denemenin ikinci yılında azot oranı arttıkça 3-octanol oranında düşüş olmuştur. Nitekim; dekara 0,5 ve $10 \mathrm{~kg}$ azot uygulamalarında denemenin birinci yılında sirası ile $\% 0.42, \% 0.62$ ve $\% 0.50$, ikinci yılında ise $\% 0.62, \% 0.39$ ve $\% 0.38$ oranında 3-octanol belirlenmiştir (Çizelge 9). Pek çok araştırıcl, nanenin uçucu yağ oranının ve kompozisyonunun; yetiştirildiği ekolojiye, türe, yıllara, gübrelemeye, sulamaya, hasat dönemine (Smith and Levi 1961; Thomas ve ark. 1961; Özgüven ve Kırıcı 1998) bağlı olduğunu belirtmişlerdir.

Denemenin birinci yılında dekara 0.5 ve $10 \mathrm{~kg}$ fosfor dozlarına göre genotiplerde belirlenen ortalama 3octanol oranı sırasıyla $\% 0.47, \% 0.54$ ve $\% 0.53$ olmuş en yüksek 3-octanol oranı dekara 5 kg'lı fosfor dozunda (\%0.54) tespit edilmiştir. Denemenin ikinci yılında ise fosfor dozu arttıkça 3-octanol oranı da artmıştır (\%0.45, \%0.46 ve \%0.49) (Çizelge 9). 
Çizelge 7. Azot ve fosfor dozlarına göre nane genotiplerinin $\beta$-pinene oranı (\%)

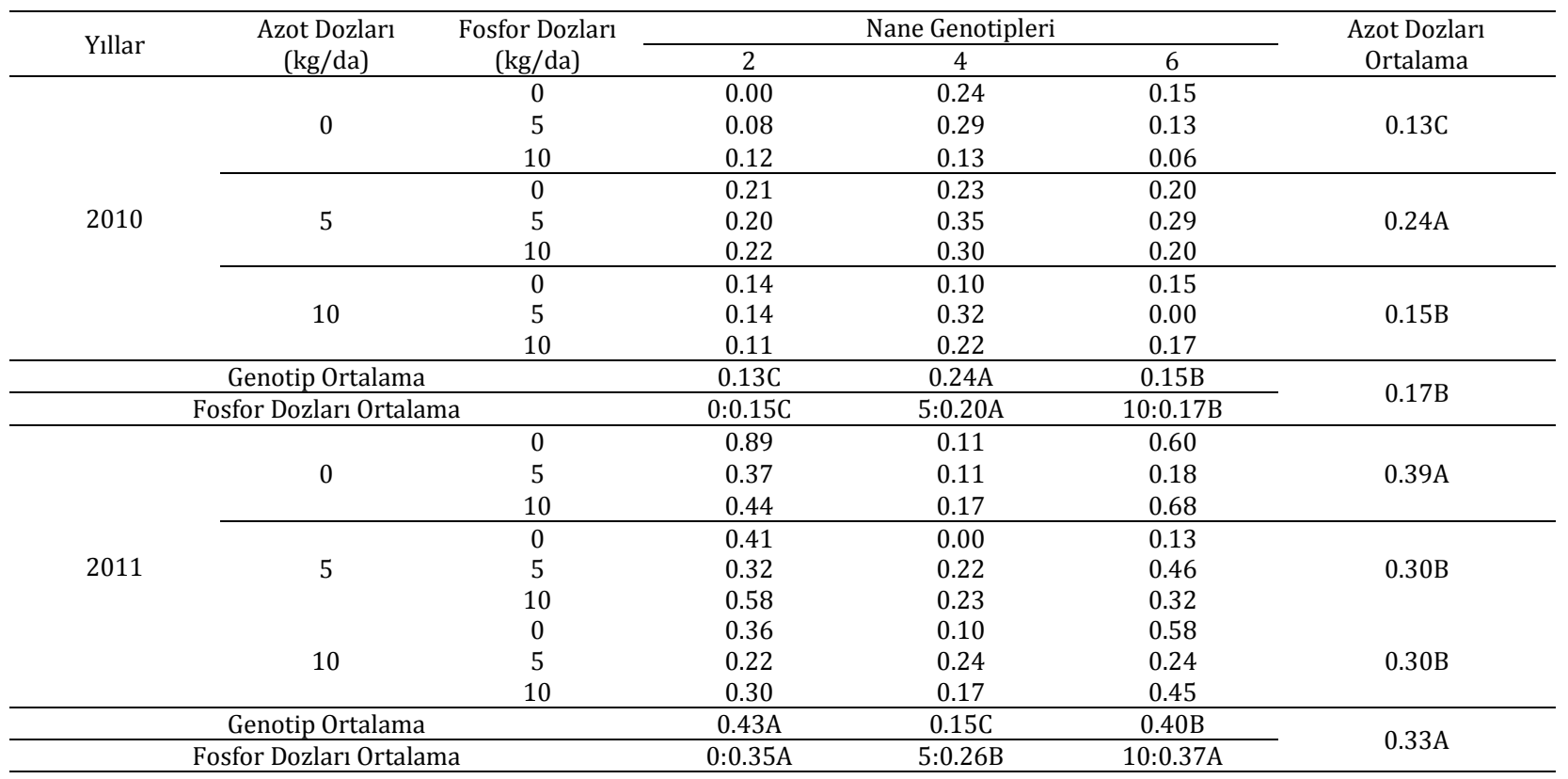

*Büyük harfle işaretlenen ortalamalar arasındaki farklar $(p<0.01)$, küçük harfle işaretlenenler ( $<<0.05)$ ihtimal sınırlarına göre önemlidir.

Çizelge 8. Azot ve fosfor dozlarına göre nane genotiplerinin $\beta$-pinene oranına ait varyans analiz sonuçları

\begin{tabular}{cccc}
\hline \multirow{2}{*}{ Varyasyon Kaynakları } & \multirow{2}{*}{ SD } & 2010 & F değerleri \\
\cline { 3 - 3 } & & 2011 & $59.642^{* *}$ \\
Azot (A) & 2 & $1078.575^{* *}$ & $63.137^{* *}$ \\
Fosfor (F) & 2 & $143.438^{* *}$ & $447.647^{* *}$ \\
Genotipler (G) & 4 & $53.315^{* *}$ & $90.160^{* *}$ \\
AxF & 4 & $57.260^{* *}$ & $55.793^{* *}$ \\
AxG & 4 & $189.918^{* *}$ & $61.789^{* *}$ \\
FxG & 8 & $176.541^{* *}$ & $38.787^{* *}$ \\
AxFxG & 54 & & \\
Hata & & \\
\hline
\end{tabular}

*Işaretli F değerleri $(\mathrm{p}<0.05),{ }^{* *}$ işaretli $\mathrm{F}$ değerleri ise $(\mathrm{p}<0.01)$ ihtimal sınırında önemlidir.

Deneme sonuçları Sartoratto ve ark., (2004)'un $M$. spicata'da tespit etmiş olduğu 3-octanol miktarından (\%0.00) yüksek, Telci et. al., (2010)'un belirttiği sinırlar (\%0.07-1.01) içinde olmuştur. Bunun sebebi olarak Özgüven ve Kırıcı (1999)'nın da belirttiği gibi nane türlerinde vejetasyon süresi, ıșık yoğunluğu, rüzgar gibi ekolojik faktörlerden dolayı, verim, verim ile ilgili özellikler yanında uçucu yağ oranı ve uçucu yağ bileșenlerinin de bölgelere göre farklı olmasından kaynaklandığı düşünülmektedir.

Birinci deneme yılında 4 no'lu genotip 3-octanol oranı yönünden ilk sırayı alırken (\%0.58), denemenin ikinci yılında son sırayı (\%0.16) almıştır. 6 no'lu genotip $(\% 0.46)$ ise denemenin birinci yılında son sırada, ikinci yılında ise ilk sırada (\%0.66) bulunmaktadır. 2 no'lu genotipin 3-octanol bileşeni birinci deneme yılında \%0.50, ikinci deneme yllında \%0.58 olmuştur (Çizelge 9).

\section{p-cymol oranı}

Artan azot dozu $(0,5,10 \mathrm{~kg} / \mathrm{da})$ uygulaması birinci deneme yılında p-cymol oranını yükseltmiş $(\% 0,40$, $\% 0.43, \% 0.44$ ), ikinci deneme yılında ise dekara 0 kg'lık dozda en fazla $(\% 0,42)$ olurken, dekara 5 kg'lık azot dozunda $(\% 0,26)$ düşüş, dekara 10 kg'lık dozda ise $(\% 0,40)$ tekrar artış olmuştur (Çizelge 11).

Birinci deneme yılında fosfor dozları arttıkça pcymol bileşeni azalmıştır. Şöyle ki; dekara 0,5 ve 10 kg'lık fosfor dozlarının uygulanması ile nane genotiplerinin ortalaması olarak belirlenen p-cymol oranları sırası ile $\% 0.45, \% 0.42$ ve $\% 0.40$ olmuştur. Denemenin ikinci yılında ise en fazla p-cymol bileşeni $10 \mathrm{~kg}$ 'lık fosfor dozunda (\%0.53), en az ise 5 
kg'lık fosfor dozunda $(\% 0,27)$ belirlenmiştir (Çizelge 11).

Birinci deneme yılında en yüksek p-cymol oranı 6 no'lu genotipte $(\% 0.53)$ meydana gelirken, bu genotipi 2 no'lu $(\% 0,42)$ ve 4 no'lu genotip $(\% 0.32)$ takip etmiştir. İkinci deneme yılında ise 2 ve 6 no'lu genotiplerin p-cymol oranları aynı (\%0.45), 4 no'lu genotipin ise \%0.19 olmuştur (Çizelge 11).

Çizelge 9. Azot ve fosfor dozlarına göre nane genotiplerinin 3-octanol oranı (\%)

\begin{tabular}{|c|c|c|c|c|c|c|}
\hline \multirow{2}{*}{ Yıllar } & \multirow{2}{*}{$\begin{array}{l}\text { Azot Dozları } \\
(\mathrm{kg} / \mathrm{da})\end{array}$} & \multirow{2}{*}{$\begin{array}{c}\text { Fosfor Dozları } \\
(\mathrm{kg} / \mathrm{da})\end{array}$} & \multicolumn{3}{|c|}{ Nane Genotipleri } & \multirow{2}{*}{$\begin{array}{c}\text { Azot Dozlarl } \\
\text { Ortalama }\end{array}$} \\
\hline & & & 2 & 4 & 6 & \\
\hline \multirow{9}{*}{2010} & \multirow{3}{*}{ 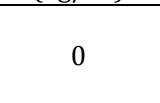 } & 0 & 0.17 & 0.48 & 0.41 & \multirow{3}{*}{$0.42 \mathrm{C}$} \\
\hline & & 5 & 0.46 & 0.55 & 0.39 & \\
\hline & & 10 & 0.58 & 0.50 & 0.30 & \\
\hline & \multirow{3}{*}{5} & 0 & 0.65 & 0.70 & 0.49 & \multirow{3}{*}{$0.62 \mathrm{~A}$} \\
\hline & & 5 & 0.58 & 0.67 & 0.66 & \\
\hline & & 10 & 0.53 & 0.60 & 0.69 & \\
\hline & \multirow{3}{*}{10} & 0 & 0.55 & 0.36 & 0.42 & \multirow{3}{*}{$0.50 \mathrm{~B}$} \\
\hline & & 5 & 0.56 & 0.82 & 0.20 & \\
\hline & & 10 & 0.43 & 0.57 & 0.59 & \\
\hline \multicolumn{3}{|c|}{ Genotip Ortalama } & $0.50 \mathrm{~B}$ & $0.58 \mathrm{~A}$ & $0.46 \mathrm{C}$ & \multirow{2}{*}{$0.52 \mathrm{~A}$} \\
\hline \multicolumn{3}{|c|}{ Fosfor Dozları Ortalama } & $0: 0.47 \mathrm{C}$ & $5: 0.54 \mathrm{~A}$ & $10: 0.53 \mathrm{~B}$ & \\
\hline \multirow{9}{*}{2011} & & 0 & 1.02 & 0.20 & 1.20 & \multirow{3}{*}{$0.62 \mathrm{~A}$} \\
\hline & 0 & 5 & 0.56 & 0.10 & 0.57 & \\
\hline & & 10 & 0.51 & 0.17 & 1.26 & \\
\hline & & 0 & 0.49 & 0.00 & 0.54 & \multirow{3}{*}{$0.39 \mathrm{~B}$} \\
\hline & 5 & 5 & 0.38 & 0.22 & 0.79 & \\
\hline & & 10 & 0.52 & 0.23 & 0.37 & \\
\hline & \multirow{3}{*}{10} & 0 & 0.49 & 0.10 & 0.00 & \multirow{3}{*}{$0.38 \mathrm{~B}$} \\
\hline & & 5 & 0.66 & 0.24 & 0.64 & \\
\hline & & 10 & 0.60 & 0.17 & 0.55 & \\
\hline \multicolumn{3}{|c|}{ Genotip Ortalama } & $0.58 \mathrm{~B}$ & $0.16 \mathrm{C}$ & $0.66 \mathrm{~A}$ & \multirow{2}{*}{$0.47 \mathrm{~B}$} \\
\hline \multicolumn{3}{|c|}{ Fosfor Dozları Ortalama } & $0: 0.45 B$ & $5: 0.46 \mathrm{~B}$ & $10: 0.49 \mathrm{~A}$ & \\
\hline
\end{tabular}

*Büyük harfle işaretlenen ortalamalar arasındaki farklar $(\mathrm{p}<0,01)$, küçük harfle işaretlenenler $(\mathrm{p}<0,05)$ ihtimal sınırlarına göre önemlidir.

Çizelge 10. Azot ve fosfor dozlarına göre nane genotiplerinin 3-octanol oranına ait varyans analiz sonuçları

\begin{tabular}{cccc}
\hline Varyasyon Kaynakları & \multirow{2}{*}{ SD } & \multicolumn{2}{c}{ F değerleri } \\
\cline { 3 - 4 } & & 2010 & 2011 \\
Azot (A) & 2 & $2540.778^{* *}$ & $8.363^{* *}$ \\
Fosfor (F) & 2 & $421.778^{* *}$ & $1644.197^{* *}$ \\
Genotipler (G) & 2 & $1048.444^{* *}$ & $266.170^{* *}$ \\
AxF & 4 & $90.778^{* *}$ & $226.781^{* *}$ \\
AxG & 4 & $151.944^{* *}$ & $47.288^{* *}$ \\
FxG & 4 & $347.944^{* *}$ & $111.455^{* *}$ \\
AxFxG & 8 & $901.944^{* *}$ & \\
Hata & 54 & & \\
\hline
\end{tabular}

*İşaretli F değerleri $(\mathrm{p}<0,05),{ }^{* *}$ işaretli $\mathrm{F}$ değerleri ise $(\mathrm{p}<0,01)$ ihtimal sınırında önemlidir.

\section{Sonuç}

Dekara 5 kg'lık azot dozlarında, 2010 deneme yılında $\alpha$-pinene, $\beta$-phellandrene, $\beta$-pinene, 3-octanol oranlarının kontrol ve $10 \mathrm{~kg} / \mathrm{da} \mathrm{N}$ uygulamasına göre, $10 \mathrm{~kg} / \mathrm{da}$ azot uygulamasının ise p-cymol bileșenini diğer uygulamalara göre artırdığı tespit edilmiștir. İncelenen bütün bileșenler en yüksek oranda 2011 yılında azot uygulaması yapılmamış parsellerde elde edilmiş, p-cymol oranı hariç ikinci en yüksek bileşen miktarları $5 \mathrm{~kg} / \mathrm{da} \quad \mathrm{N}$ uygulamasında belirlenmiştir. Uygulanan fosfor dozlarında 2010 deneme yılında dekara; 5 kg azot uygulamasında p-cymol oranı dışında diğer bütün bileşenlerde en yüksek değerler tespit edilmiş, pcymol'de ise en yüksek oran gübreleme yapılmamış parsellerde belirlenmiștir.

Denemenin ikinci yılında en yüksek $\alpha$-pinene, $\beta$ phellandrene oranları fosfor gübrelemesi yapılmayan parsellerden, en yüksek $\beta$-pinene, 3octanal ve p-cymol oranları dekara $10 \mathrm{~kg}$ fosfor uygulamasından elde edilmiştir. 
Çizelge 11. Azot ve fosfor dozlarına göre nane genotiplerinin p-cymol oranı (\%)

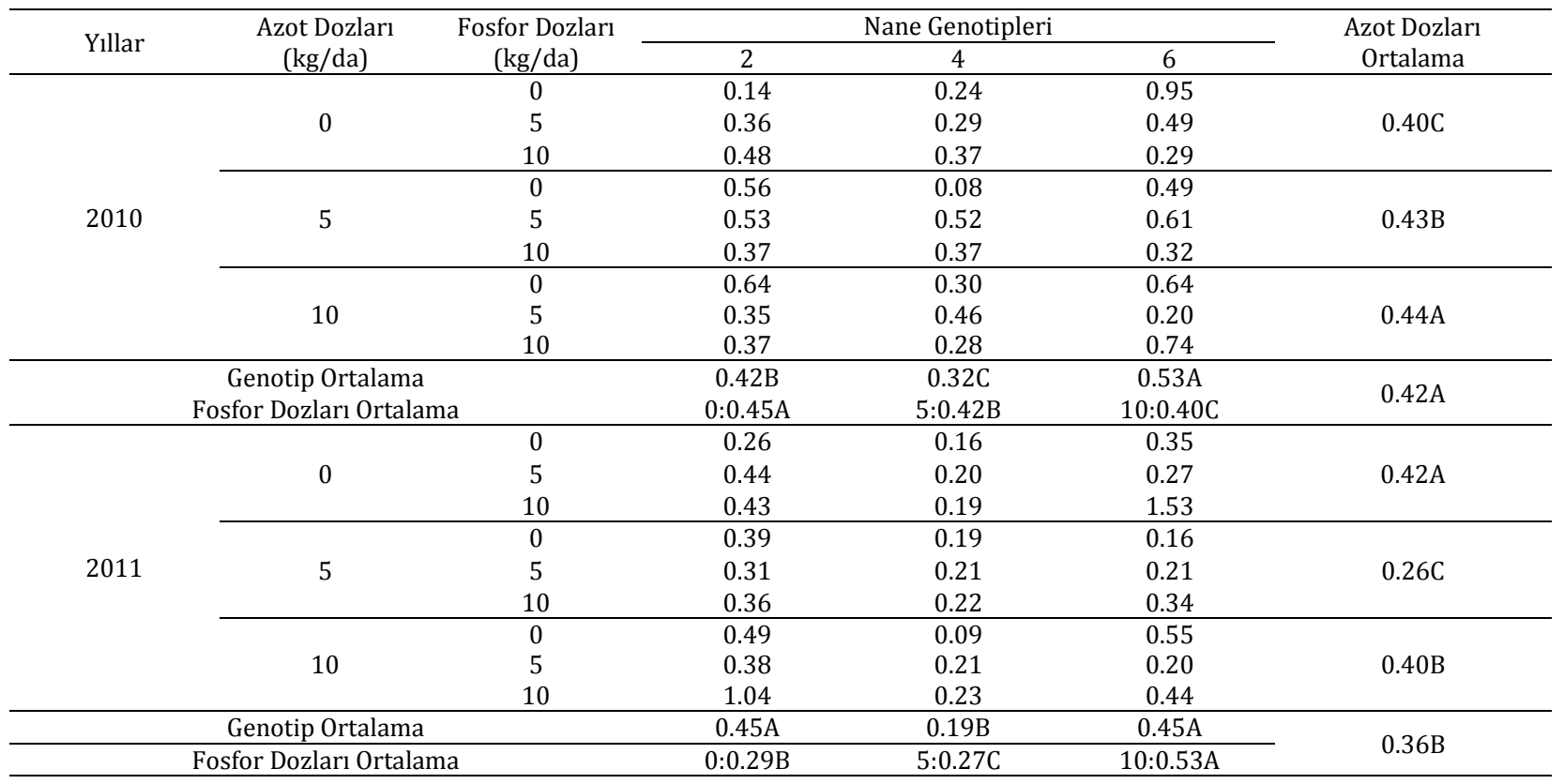

*Büyük harfle işaretlenen ortalamalar arasındaki farklar $(p<0,01)$, küçük harfle işaretlenenler $(p<0,05)$ ihtimal sınırlarına göre önemlidir.

Çizelge 12. Azot ve fosfor dozlarına göre nane genotiplerinin p-cymol oranına ait varyans analiz sonuçları

\begin{tabular}{cccc}
\hline \multirow{2}{*}{ Varyasyon Kaynakları } & \multirow{2}{*}{ SD } & 2010 & F değerleri \\
\cline { 3 - 4 } & & $117.444^{* *}$ & 2011 \\
Azot (A) & 2 & $168.778^{* *}$ & $673.413^{* *}$ \\
Fosfor (F) & 2 & $2760.778^{* *}$ & $752.333^{* *}$ \\
Genotipler (G) & 2 & $935.111^{* *}$ & $144.653^{* *}$ \\
AxF & 4 & $406.611^{* *}$ & $335.773^{* *}$ \\
AxG & 4 & $1426.944^{* *}$ & $202.073^{* *}$ \\
FxG & 4 & $1392.528^{* *}$ & $271.063^{* *}$ \\
AxFxG & 8 & \\
Hata & 54 & & \\
\hline
\end{tabular}

*Ișaretli F değerleri $(\mathrm{p}<0,05)$, ** ișaretli $\mathrm{F}$ değerleri ise $(\mathrm{p}<0,01)$ ihtimal sınırında önemlidir.

Genotip ortalamalarına göre birinci deneme yılında $\alpha$-pinene, $\beta$-pinene ve 3 -octanol bileşenleri 4 no'lu genotipte, ikinci deneme yılında ise $\beta$-pinene dıșındaki tüm bileșenlerde en yüksek oran 6 no'lu genotipte öne çıkmıştır.

Ülkemizin ve çiftçimizin ekonomik şartları, Mentha bitkisinde verim değerleri ve incelenen bileşen oranları değerlendirildiğinde dekara $5 \mathrm{~kg}$ azot ve fosfor gübrelemesinin ve uçucu yağ bileşenlerinin oranı bakımından 4 ve 6 no'lu genotiplerin uygun olacağı düşünülmektedir.

\section{Kaynaklar}

Arslan, Y., Katar, D., Subaşı, İ., 2010. Ankara Ekolojik Koşullarında Japon Nanesi (Mentha arvensis L.) Bitkisinde Uçucu Yağ ve Bileșenlerinin Ontogenetik
Varyabilitesinin Belirlenmesi. GOÜ, Ziraat Fakültesi Dergisi, 27(2): 39-43.

Bașer, K.H.C., Kürkçüoğlu, M., Tarımcılar, G., Kaynak G., 1999. Essential oils of Mentha species from northern Turkey, J. Essent. oil Res., 11: 579-588.

Baytop, T.,1999. Türkiye'de Bitkiler ile Tedavi. İstanbul: Nobel Kitabevi, 302-304.

Ceylan, A., 1987. Tıbbi Bitkiler II (Uçucu Yağ İçerenler). Ege Üniversitesi, Ziraat Fakültesi Yayın. No:481, Bornova, İzmir.

Chauhana, R.S., Kaul M.K., Shahi, A.K., Kumar, A., Rama, G., Tawab, A., 2009. Chemical composition of essential oils in Mentha spicata L. accession [IIIM(J)26] from North-West Himalayan region, India. Industrial Crops and Products 29: 654-656. 
Chowdhury, J.U., Nandi, N.C., Uddina, M., Rahmanb, M., 2007. Chemical Constituents of Essential Oils from Two Types of Spearmint (Mentha spicata L. and M. cardiaca L.) Introduced in Bangladesh. Bangladesh J. Sci. Ind. Res. 42(1): 79-82.

Clark, R.J., Menary, R.C., 1982. Environmental and cultural factors affecting the yield and composition of peppermint oil. VII. International Congress of Essential Oil. 14:74-79.

Davis, P.H., 1982. Flora of Turkey and the East Aegean Island, Edinburg Univ. Press, Edinburg, 7: 384-394.

Eyüpoğlu, F., 2002. Türkiye Gübre Gereksinimi Tüketimi ve Geleceği. T.C. Tarım ve Köyişleri Bakanlığı. Köy Hizmetleri Genel Müdürlüğü. Toprak ve Gübre Araştırma Enstitüsü İșletme Müdürlüğü Yayınları. Teknik Yayın No: T-2. Genel Yayın No:2. Ankara.

Hadjiakhoondi, A., Aghel, N., Zamanızadeh-Nadgar, N., Vatanıdoost, H., 2000. Chemical and Biological Study of Mentha spicata L. Essential Oil From İran. Doru Journal of Pharmaceutical Sciences 8 (1):1921.

Kireççi, O.A., 2006. Bazı Sentetik Hormonların (giberelik asit, spermin, spermidin, putresin) Fesleğen (Ocimum basilicum) Bitkisinde Morfolojik Yapı ve Uçucu Yağ Kalitesine Etkisi. Kahramanmaraş Üni. Fen Bilimleri Ens. Yüksek Lisans Tezi.

Kofidis, G., Bosabalidis, A., Kokkini, S., 2004. Seasonal Variation of Essential Oils in a Linalool-Rich Chemotype of Mentha spicata Grown Wild in Greece. J. Essent. Oil Res., 16: 469-472.

Kokkini, S., 1991. Chemical races within the Genus Mentha L. Modern Methods of Plant Analysis New Series (Linskens, H.F. and J.F. Jackson, Eds.), SpringerVerlag Berlin, Heidelberg, 12:63-77.

Kokkını, S., Karousou, R., Lanaras, T., 1995. Essential Oils of Spearmint (Carvone-rich) Plants from the Island of Crete (Greece). Biochemical Systematics and Ecology,23 (4): 425-430.

Marotti, M., Dellacecca, V., Piccaglia, R., Giovanelli, E. 1993. Effect of harvesting stage on the yield and essential oil composition of peppermint (Mentha x piperita L.) Acta Hortic. 344:370-379.

Martins Maldao, M., Beirao-da-Costa, S., Neves, C., Cavaleiro, C., Salgueiro, E., Beirao-da-Costa L., M., 2004. Olive oil flavoured by the essential oils of
Mentha x piperita and Thymus mastichina L. Food Quality and Preference 15: 447-452.

Misra, L.N., Tyagi, B.R., Thakur, R.S., 1989. Chemotypic variation in Indian Spearmint. Planta Med., 55:575576.

Özgüven, M., Kırıcı S., 1998. In Situ Conservation of Aromatic Plants in Southeastern Turkey. Wild Mentha Species. The Proceeding of International on In situ Conservation of Plant Genetic Diversity. CRIFC, Turkey.

Özgüven, M., Kırıcı S., 1999. Farklı Ekolojilerde Nane (Mentha) Türlerinin Verim İle Uçucu Yağ Oran ve Bileşlerinin Araştırılması. Tr. J. of Agriculture and Forestry. 23: 465-472.

Sartoratto, A., Machado, A.L.M., Delarmelina, C., Figueira, G.M., Duarte, M.C.T., Rehder, V.L.G., 2004. Composition and Antimicrobial Activity of Essential Oils from Aromatic Plants Used in Brazil. Brazilian Journal of Microbiology, 35:275-280.

Sezen, Y., 1991. Gübreler ve Gübreleme Ders Notları. Atatürk Üniversitesi Ziraat Fakültesi Toprak Bölümü, Erzurum, 39-41.

Smith, D., Levi, L., 1961. Treatment of compositional data fort he characterization of essential oils. Determination of geographical origis of pepermint oils by gas chromatographic analysis. Journal Agricultre Food Chemistry, 9:230-44.

Tanker, N., Koyuncu, M., Coşkun, M., 1998. Farmasötik Botanik. Ankara: Ankara Üniversitesi Eczacilık Fakültesi Yayınları, 78, 341.

Telci, İ., 2001. Farklı Nane (Mentha spp) Klonlarının Bazı Morfolojik, Tarımsal ve Teknolojik Özelliklerinin Belirlenmesi Üzerinde Bir Araștırma. Gaziosmanpaşa Üniversitesi Fen Bilimleri Enstitüsü, Doktora Tezi, 160, Tokat.

Telci, İ., Demirtas, İ., Bayram, E., Arabaci, O., Kaçar, O., 2010. Environmental variation on aroma components of pulegone/piperitone rich spearmint (Mentha spicata L.). Industrial Crops and Products 32: 588-592.

Yıldız, N., 1994. Araştırma Deneme Metodları II. Baskı. Atatürk Üniversitesi Ziraat Fakültesi Yay. No.697 Erzurum.

Yücel, E., 2007. Tıbbi Bitkiler 1. Ders Kitabı. Eskişehir 